\title{
Stabilisation of high-sulphide tailings with alkali activated fly ash - mechanical performance
}

\author{
Cristelo Nuno ${ }^{1, *}$, Coelho João ${ }^{2}$, Miranda Tiago ${ }^{2}$, Sousa Luis ${ }^{1}$, Fernández-Jiménez Ana ${ }^{3}$ and Oliveira Mafalda $^{4}$ \\ ${ }^{1}$ University of Trás-os-Montes e Alto Douro, 5001-801 Vila Real, Portugal \\ ${ }^{2}$ University of Minho, 4800-058 Guimarães, Portugal \\ ${ }^{3}$ Instituto de Ciencias de la Construcción 'Eduardo Torroja', 28033 Madrid, España \\ ${ }^{4}$ SOMINCOR, S.A., 7780-909 Castro Verde, Portugal
}

\begin{abstract}
Mine tailings could represent a step forward in terms of the quality of the aggregates that usually accepted in civil engineering applications, due to their specific weight and compressive strength. The Neves-Corvo copper mine produces approximately 3 million tons of tailings every year, which could supply several construction works, at least in the south of Portugal. Nevertheless, this industrial waste requires stabilisation, not only due to their high sulphur content, but also due to mechanical performance demands. This paper focus on the stabilisation, without previous thermal treatment, of the mine tailings from Neves-Corvo.
\end{abstract}

\section{Introduction}

The Neves-Corvo underground copper-zinc mine, located $200 \mathrm{~km}$ south of Lisbon, produces 2.9 million tons of tailings annually, of which approximately two thirds are landfilled. It's a world-class mine due to the extremely high copper and zinc contents. Its deposition requires a continuous financial and technical effort in order to guarantee safe and sound deposits, and currently constitutes the single major concern associated with this type of mineral exploration. At the same time, and due to its origin, the mechanical properties of this waste are very attractive for many applications, either structural and/or durability-dependent. However, this waste is acidgenerator, which makes it almost impractical to use in even high-level applications (in which case the financial cost would be less decisively), let alone in more common applications, like embankments or road pavements. Apart from concrete, transport infrastructures constitute a feasible application to decontaminate mine tailings (MT), mainly to the high-volume of granular material demanded. Such replacement of natural (and thus environmental impacting aggregate) by an industrial residue, reduces the consumption of natural resources and decreases the volume of materials to be landfilled.

The inclusion of this material in alkali activated mortar and concrete constitutes a fairly recent worldwide research target, with several studies produced in the last 5-10 years. Some studies have focused mainly on the use of the MT in a precursor role, albeit requiring a previous thermic treatment, and less on its use as a filler and/or courser aggregate. Pacheco-Torgal et al [1] studied the microstructure and mechanical behaviour of geopolymeric mine waste binders, concluding that it showed a significant early-age strength, resulting from the enhanced bonding between the binder and the aggregates. In another paper from the same authors [2], assessing different properties of the same composite, such as workability and setting time, among others, it was concluded that the experimental methods applied to cement-based mortars are not feasible in this case. A thorough investigation on the hydration products, also from Pacheco-Torgal et al [3], showed that mechanical strength is closely related with the mineralogical evolution of the aluminosilicate gel, since new crystalline phases were formed. In terms of durability, a comparison between the abrasion and acid resistance of Portland cement-based concrete and mine waste mud mixtures was developed [4], concluding that the latter showed a superior performance than the former, while also demonstrating that the activated mine waste material was inert, and was thus suitable for use as a building material. More recently, Kastiukas et al [5], while studying the ideal preparation conditions of mine waste and waste glass blends, activated with sodium hydroxide and sodium silicate, concluded that the addition of soluble silica (from the glass) is beneficial to the degree of amorphicity of the mine waste, therefore dispensing the calcination step. Kuranchie et al [6] studied the production of bricks alkali activated mine waste, approaching issues such as the initial setting time, curing temperature, curing time and activator content, reaching a maximum compression strength of $50 \mathrm{MPa}$, which is above the minimum threshold imposed by both American and Australian authorities. Although very promising, the mentioned studies focused on MT resulting from other minerals than copper, namely from tungsten and gold mines. Regarding the use of MT from copper mines, in a precursor role, several studies have been presented showing the feasibility of this material

\footnotetext{
* Corresponding author: ncristel@utad.pt
} 
[7-9]. Finally, some studies have also produced mixtures of tailings and fly ash or slag, in order to adjust the most influential ratios in alkali activation, especially $\mathrm{Si} / \mathrm{Al}$ $[10,11]$.

This paper focus on the viability of stabilising mine tailings from a copper mine, using alkali activated binary systems. The MT was mixed with fly ash (FA), using different MT/FA weight ratios, and activated with a combination of sodium hydroxide and sodium silicate. Additional variables tested were sodium hydroxide concentration and hydroxide / silicate weight ratio. Mechanical behaviour was assessed through uniaxial compression strength tests, while microstructural and mineralogical characterisation was achieved using scanning electron microscopy, X-ray energy dispersion, $\mathrm{X}$-ray diffraction and infrared spectroscopy.

\section{Experimental}

\subsection{Materials}

The chemical characterisation of the mine tailing (MT) sample, recovered from the Neves-Corvo facility, showed the significant presence of $\mathrm{SO}_{3}(41 \%)$ and $\mathrm{Fe} 2 \mathrm{O} 3$ (28\%), which together make approximately $70 \%$ of the composition. The fly ash (FA), obtained from the Portuguese thermos-electric power 'Central do Pego', was composed mainly by $\mathrm{SiO} 2$ (51\%) and $\mathrm{Al} 2 \mathrm{O} 3$ (23\%). Their full chemical composition is presented in Table 1.

Particle size distribution of the MT and FA is presented in Figure 1. The specific gravity of the FA was $21.75 \mathrm{kN} / \mathrm{m} 3$, while the MT showed a significantly higher value of $32.85 \mathrm{kN} / \mathrm{m} 3$.

Table 1. Chemical composition of the MT and FA.

\begin{tabular}{|c|c|c|}
\hline Element & $\begin{array}{c}\text { FA } \\
(\mathbf{w t} \%)\end{array}$ & $\begin{array}{c}\text { MT } \\
(w t \%)\end{array}$ \\
\hline $\mathrm{Na}_{2} \mathrm{O}$ & 1.81 & 0.41 \\
\hline $\mathrm{SiO}_{2}$ & 51.5 & 18.5 \\
\hline $\mathrm{Al}_{2} \mathrm{O}_{3}$ & 23.1 & 7.25 \\
\hline $\mathrm{MgO}$ & 2.19 & 1.48 \\
\hline $\mathrm{K}_{2} \mathrm{O}$ & 3.05 & 0.62 \\
\hline $\mathrm{CaO}$ & 2.12 & 0.96 \\
\hline $\mathrm{TiO}_{2}$ & 1.49 & 0.15 \\
\hline $\mathrm{Fe}_{2} \mathrm{O}_{3}$ & 12.8 & 27.5 \\
\hline $\mathrm{ZnO}$ & 0.05 & 1.15 \\
\hline $\mathrm{ZrO}_{2}$ & 0.05 & - \\
\hline $\mathrm{BaO}$ & 0.11 & - \\
\hline $\mathrm{PbO}$ & 0.03 & 0.40 \\
\hline $\mathrm{As}_{2} \mathrm{O}_{3}$ & - & 0.35 \\
\hline $\mathrm{CuO}$ & 0.04 & 0.44 \\
\hline $\mathrm{SO}_{3}$ & 1.25 & 40.6 \\
\hline $\mathrm{Co}_{3} \mathrm{O}_{4}$ & - & 0.04 \\
\hline $\mathrm{Cr}_{2} \mathrm{O}_{3}$ & - & 0.04 \\
\hline $\mathrm{Sb}_{2} \mathrm{O}_{3}$ & - & 0.05 \\
\hline $\mathrm{MnO}$ & 0.11 & 0.08 \\
\hline $\mathrm{NiO}$ & 0.03 & - \\
\hline $\mathrm{P}_{2} \mathrm{O}_{5}$ & 0.28 & - \\
\hline $\mathrm{Rb}_{2} \mathrm{O}$ & 0.03 & - \\
\hline $\mathrm{SrO}$ & 0.08 & - \\
\hline
\end{tabular}

Different combinations of sodium hydroxide ( $\mathrm{SH}$ ) and sodium silicate (SS) were used to activate the solid precursors, with $\mathrm{SS} / \mathrm{SH}$ weight ratios ranging from 0.5 to 1.25. The $\mathrm{SH}$ was dissolved in deionised water in order to obtain $7.5,10.0,12.5$ and 15.0 molal concentrations.

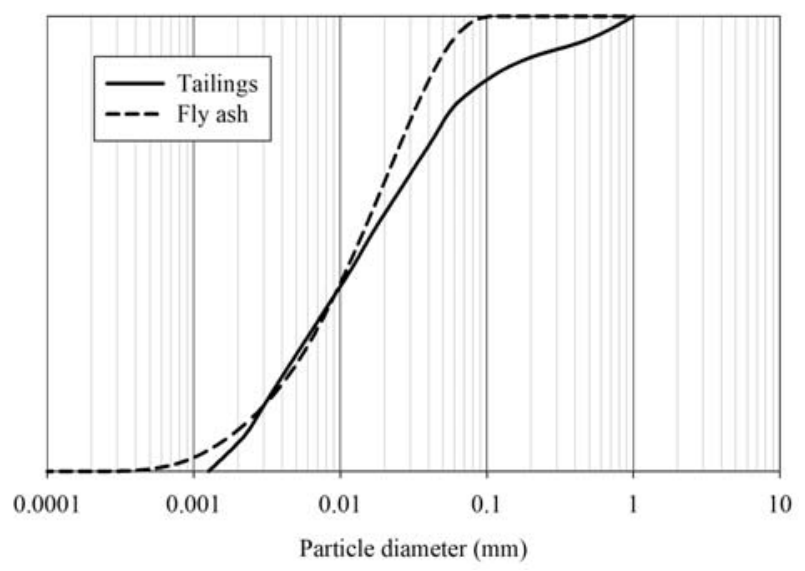

Fig. 1. Particle size distribution of the MT and FA.

\subsection{Mixtures preparation and strength testing}

The mixtures tested (Table 2) were designed to study three different variables: activator/ash weight ratio; $\mathrm{SH}$ concentration; SS/SH weight ratio.

A standard Proctor test was used to assess the maximum dry unit weight and correspond water content during compaction. This test was performed on mixture $\mathrm{S} 1.3$, and a dry unit weight of $1.974 \mathrm{~g} / \mathrm{cm} 3$ and water content of $13 \%$ were obtained.

Table 2. Composition of the mixtures tested.

\begin{tabular}{|c|c|c|c|}
\hline Mix & $\begin{array}{c}\text { Activator } \\
\text { / Ash } \\
\text { (wt. ratio) }\end{array}$ & $\begin{array}{c}\text { SS / SH } \\
\text { (wt. ratio) }\end{array}$ & $\begin{array}{c}\text { SH } \\
\text { concent. } \\
\text { (molal) }\end{array}$ \\
\hline S0.0 & 0.75 & 0.50 & 7.5 \\
\hline S1.1 & 0.65 & 0.50 & 7.5 \\
S1.2 & 0.85 & 0.50 & 7.5 \\
S1.3 & 0.95 & 0.50 & 7.5 \\
\hline S2.1 & 0.75 & 0.50 & 10.0 \\
S2.2 & 0.75 & 0.50 & 12.5 \\
S2.3 & 0.75 & 0.50 & 15.0 \\
\hline S3.1 & 0.75 & 0.75 & 7.5 \\
S3.2 & 0.75 & 1.00 & 7.5 \\
S3.3 & 0.75 & 1.25 & 7.5 \\
\hline
\end{tabular}

The fabrication of the specimens started with the dry mixing of the solids (MT + FA), followed by the slowly addition of the activator, and by a subsequent 5 min period for homogenisation. The resulting mixture was then compacted inside a cylindrical mould with diameter and height of $37 \mathrm{~mm}$ and $70 \mathrm{~mm}$, respectively. The specimens were then cured at temperature/humidity of $85^{\circ} \mathrm{C} / 20 \%$, for $24 \mathrm{~h}$, and submitted to a uniaxial compressive strength (UCS) test. Three tests were performed for each UCS value. 


\subsection{Characterisation Techniques}

Microstructural and mineralogical analysis were developed for mixtures S0.0 and S2.2, namely scanning electron microscopy (SEM), coupled with X-ray energy dispersion (EDX); X-ray diffraction (between 10 and $80^{\circ}$ 20); and infrared spectroscopy (range 1600 to $400 \mathrm{~cm}-1$ ). Additionally, thin sections of the mixture S2.2 were examined under a petrographic microscope, to assess the overall morphology.

\section{Results}

\subsection{Compressive strength}

The uniaxial compression tests were performed on a servo-hydraulic, using a $10 \mathrm{kN}$ load cell, under monotonic displacement control.

\subsubsection{Influence of the activatorlash ratio}

The UCS values, as a function of the activator/ash ratio, are presented in Fig. 2. An increase in this ratio represents a decrease in the UCS, as already concluded in previous research [12]. However, in this case this was true only up to a certain value, after which the strength starts to increase - it should be noted that, in the mentioned previous research, the maximum ratio tested was 0.425 .

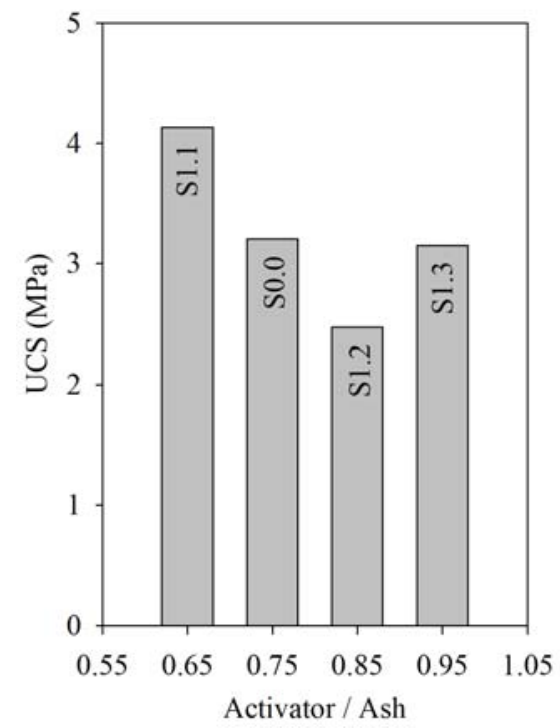

Fig. 2. UCS as a function of the activator/ash ratio.

\subsubsection{Influence of the SH concentration}

As previously concluded $[10,12]$, an increase in the concentration of the sodium hydroxide yields an increase in final compression strength (Fig. 3). This behaviour might be disrupted only if too high concentrations are used, which would affect the preparation of the mixtures and, consequently, their homogenisation. An increase in concentration favours an increase in the alkalinity, thus facilitating the dissolution of the species needed to form the structural matrix.

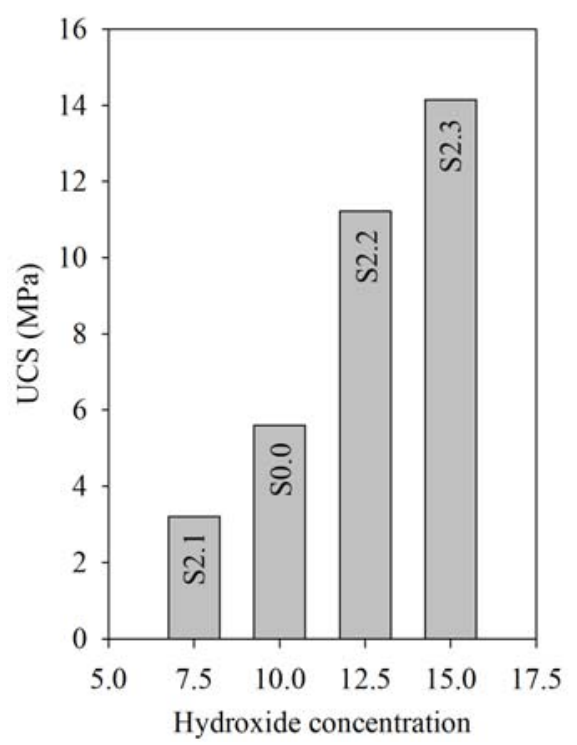

Fig. 3. UCS as a function of the SH concentration.

\subsubsection{Influence of the SS/SH ratio}

This variable appears to be the least important for the final compression strength, as shown in Fig. 4. However, the fact that an increase in the SS/SH ratio render a more stable UCS value suggests that more significant variations of this ratio might be found in the lower range, up to the 0.75 value. This is important since the total elimination of the sodium silicate from the activator composition would certainly produce cost and logistic savings.

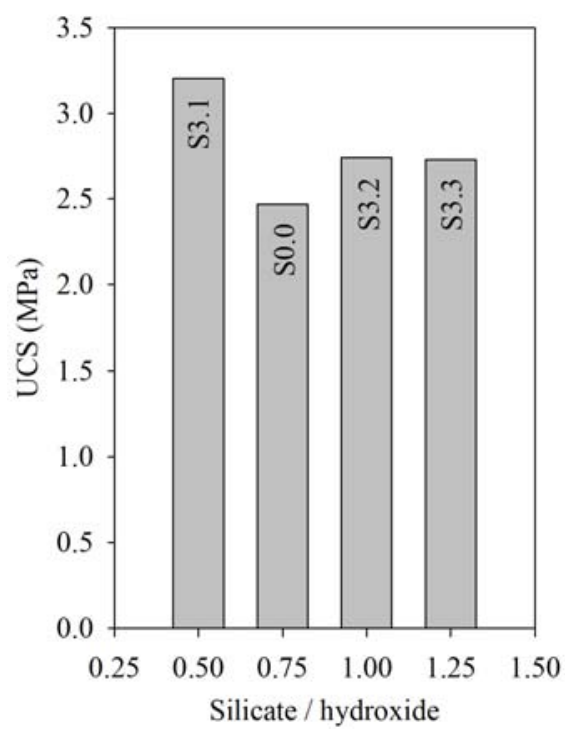

Fig. 4. UCS as a function of the SS/SH ratio.

\subsection{Microstructure and mineralogy}

The microstructural and mineralogical analysis were always performed over samples of mixture S2.2, collected after UCS tests. 


\subsubsection{Petrographic microscopy}

Fig. 5 presents the same petrographic image of S2.2, under normal and polarised light. It was taken to understand the overall particle / paste distribution. Based on these images, it is possible to conclude that an evenly distribution of the MT particles was achieved, which created a well-organised petrous skeleton.
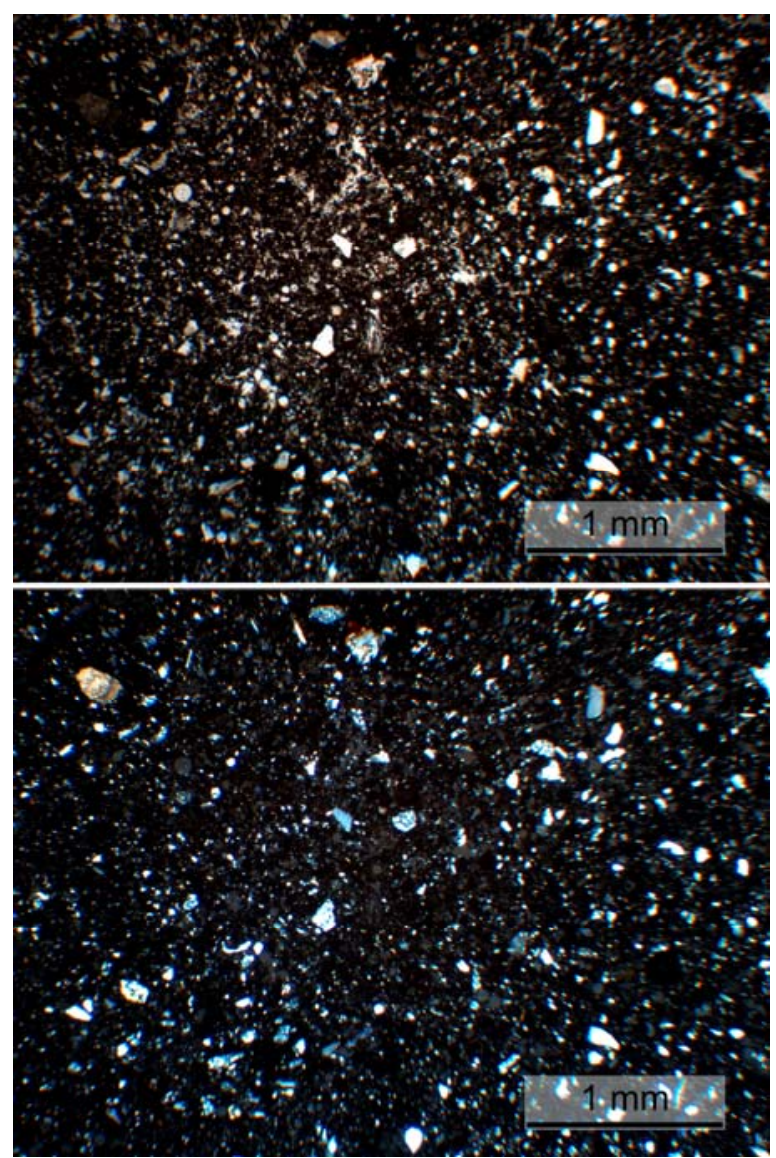

Fig. 5. Optical microscope: normal (above) and polarised (below)

\subsubsection{SEMIEDX}

Micrographs like the one presented in Fig. 6 (from the S2.2 mixture) allow an understanding of the mixture morphology, on a narrower scope than that achieved by the petrograph microscopy. This is helpful to characterise the particle / gel interface, as well as the state of the gel. The mixture seems to be well compacted and, although several partially intact ash particles are still visible, the reaction product appears to be evenly distributed, covering most FA and MT particles.

In this case, and based on the data presented in Table 3, a typical N-A-S-H gel was formed, although with a significant percentage of sulphur (17\%), along with high levels of silicon, indicating the possible capacity of the reaction products to partially contain this most undesirable, environment-threatening element present in the original MT.

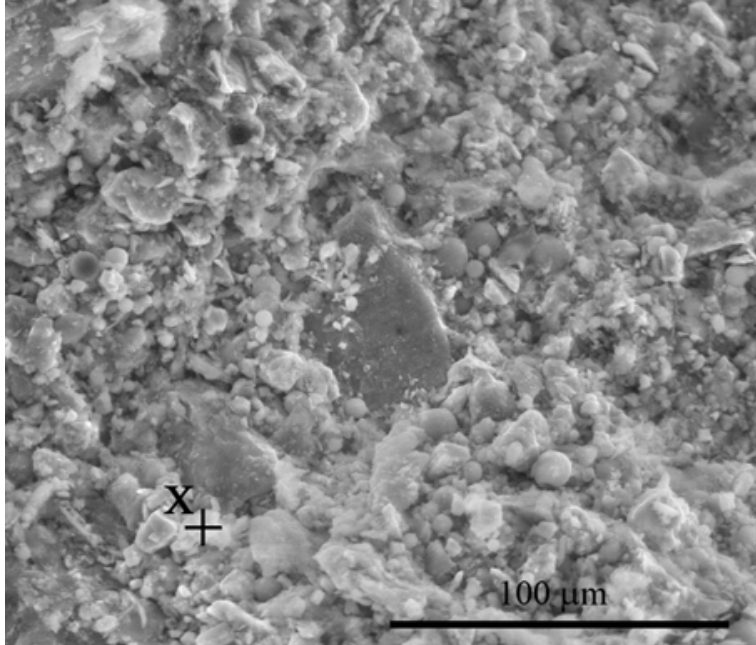

Fig. 6. SEM micrograph of the S2.2 mixture.

\subsection{3 $X R D$}

The XRD diffractograms presented in Fig. 7 reveal the presence of quartz, muscovite, pyrite and amesite in the MT; and quartz and mullite in the FA. The hump in the $18^{\circ}$ to $30^{\circ}(2 \mathrm{q})$ range in the FA indicates some level of amorphisation, necessary for the reactions to occur.

The diffractogram of the mixture S2.2 didn't show any significant new peaks. Instead, the intensity of most of the peaks originated by the FA has substantially decreased, while those associated with the MT didn't present any major reduction, highlighting the inert status of the tailings.

Table 3. EDS data from SEM micrograph shown in Fig. 6.

\begin{tabular}{|c|c|c|}
\hline Element & $\begin{array}{c}\text { General } \\
(\%)\end{array}$ & $\begin{array}{c}\text { Gel phase } \\
\text { (Point X) } \\
(\%)\end{array}$ \\
\hline $\mathrm{Na}_{2} \mathrm{O}$ & 8.9 & 2.6 \\
\hline $\mathrm{SiO}_{2}$ & 28.6 & 73.7 \\
\hline $\mathrm{Al}_{2} \mathrm{O}_{3}$ & 11.1 & 3.97 \\
\hline $\mathrm{MgO}$ & 2.1 & 0.9 \\
\hline $\mathrm{K}_{2} \mathrm{O}$ & 0.5 & 0.1 \\
\hline $\mathrm{CaO}$ & 0.6 & 0.2 \\
\hline $\mathrm{TiO}_{2}$ & 0.2 & - \\
\hline $\mathrm{Fe}_{2} \mathrm{O}_{3}$ & 6.1 & 1.8 \\
\hline $\mathrm{ZnO}$ & 0.3 & 0.1 \\
\hline $\mathrm{PbO}^{\mathrm{SnO}}$ & 0.5 & 0.1 \\
\hline $\mathrm{SO}_{3}$ & 41.2 & 16.6 \\
\hline
\end{tabular}




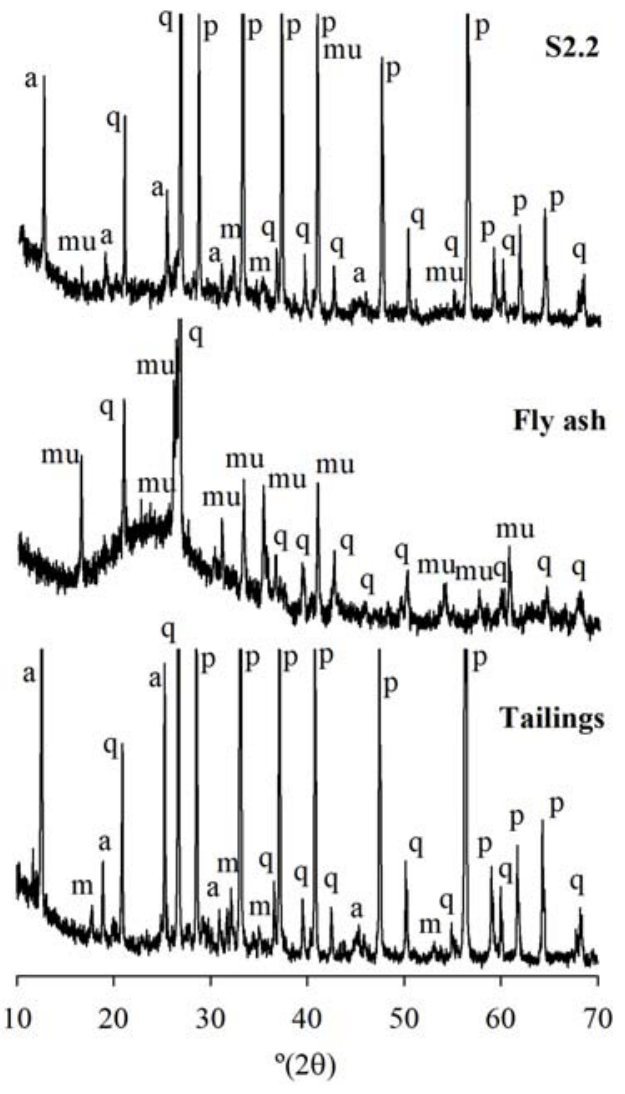

Fig. 7. XRD data of the MT, FA and S2.2; Legend: a-amesite, m-muscovite, mu-mullite, p-pyrite, q-quartz.

\subsubsection{FTIR}

Fig. 8 shows the FTIR spectra of the MT, FA and mixture S2.2. Several main peaks were identified in the 400 to $1600 \mathrm{~cm}^{-1}$ range especially in the 400 to $1400 \mathrm{~cm}^{-}$ ${ }^{1}$ interval.

The FA spectrum presents three characteristic bands, at 1020 (Al-O stretching vibrations), 773 (Si-O) and 410 (O-Si-O). The 1060 band, associated with Si-O or Al-O, is only present in the mixture $\mathrm{S} 2.2$, thus representing the formation of new bonds derived from the reactions. The bands at 980, 872 and 773, typical of $\mathrm{Si}-\mathrm{O}$ stretching vibrations, appear on the original MT and, without noticeable loss, in the S2.2 mixture, which reflects the crystalline character of the MT. A similar conclusion can be drawn for the 693 band, only in this case Al-O bonds are also included. The band at 610, typical of O-Si-O and $\mathrm{O}-\mathrm{Al}-\mathrm{O}$ bonds, appeared only in the S2.2, suggesting also the formation of new molecules, as a result of the reactions. Bands at 529, 460 and 410, found in the MT spectrum, indicate $\mathrm{O}-\mathrm{Si}-\mathrm{O}$ vibrations and were kept in the $\mathrm{S} 2.2$ spectra.

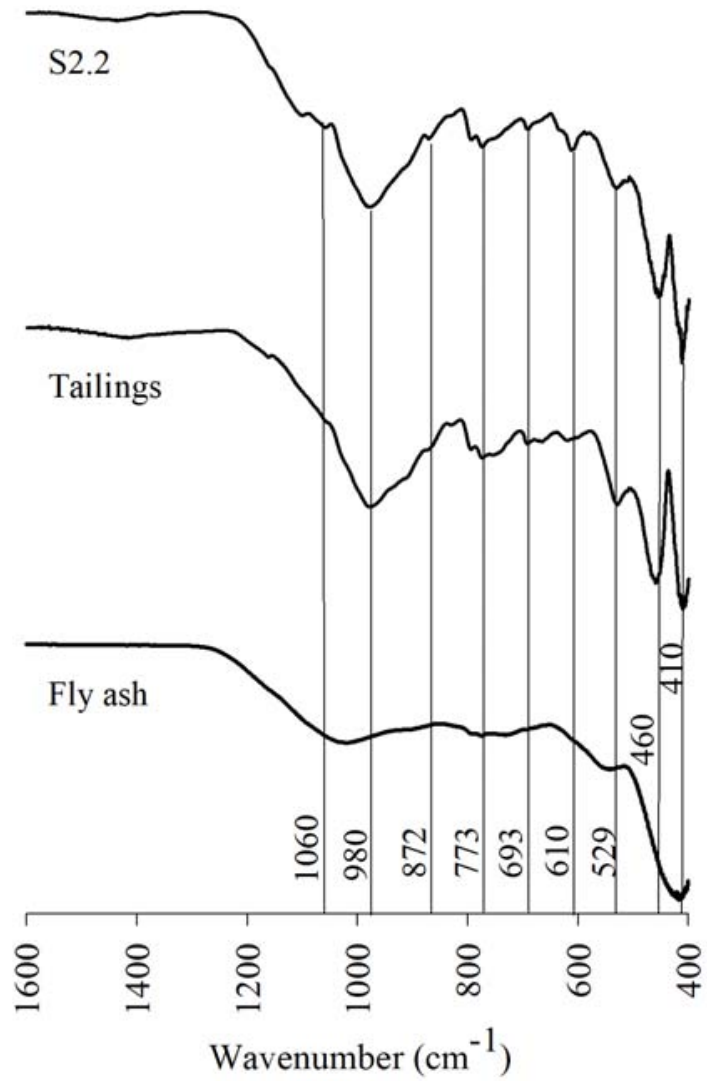

Fig. 8. FTIR data of the MT, FA and S2.2.

\subsubsection{Soluble $\mathrm{SO}_{3}$ and electrical conductivity}

The data presented in Fig. 9 shows the soluble $\mathrm{SO}_{3}$ and the electrical conductivity of the leachate recovered from leaching tests - performed according to the contents of European Standard EN12457-4 (2002) [13] - conducted on the original MT and on the S2.2 mixture, as well as of the water directly collected from the ponds.

The dissolution of $\mathrm{SO}_{3}$ presented a significant reduction after the stabilisation of the MT with alkali activated FA (down to $50 \%$, when compared with the leachate, and almost down to $33 \%$, when compared with the more ion-charged pond water). However, the electrical conductivity of the stabilised MT (mixture S2.2) showed an increase, relatively to both the leachate and the pond water. This is probably explained by the additional ions released into the leachate, during the test, resulting from the dissolution promoted during the alkali activation reactions. 


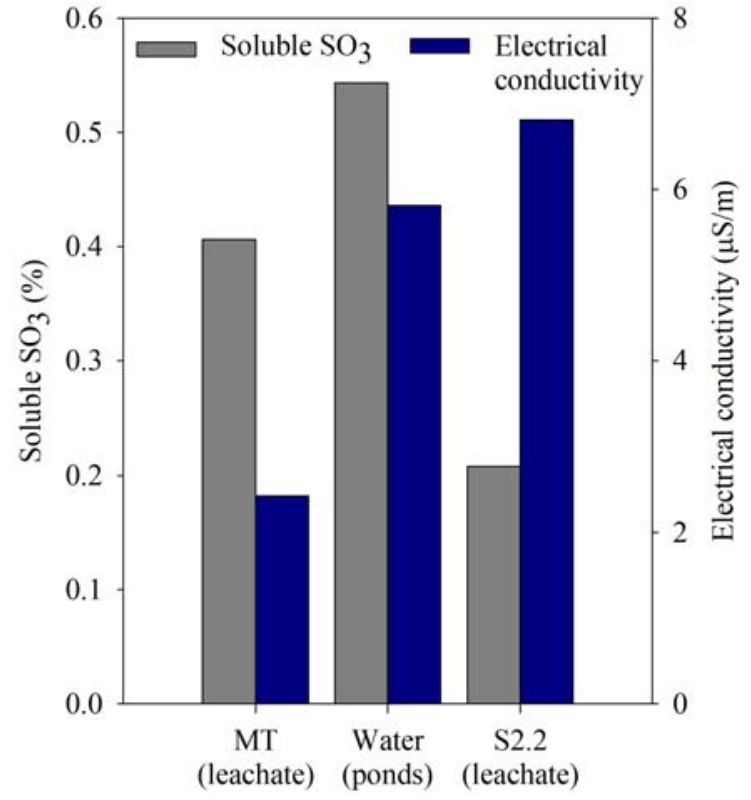

Fig. 9. Soluble $\mathrm{SO}_{3}$ and electrical conductivity of the leachate obtained from the MT and the S2.2, as well as the original water from the mine ponds.

\section{Conclusions}

In terms of mechanical behaviour, the stabilisation of mine tailings from copper extraction using alkali activated fly ash is a relatively effective procedure, which can be considered when targeting low-strength range applications $(<20 \mathrm{MPa})$, like embankments or road and railway bases and sub-bases. This procedure has the advantage of avoiding any type of thermic treatment of the tailings, in order to increase its amorphisation level, while at the same time adding only approximately $25 \%$ of fly ash, meaning that at least 75 $\mathrm{wt} \%$ of the final mixture will be composed of tailings. This is a significant aspect, since it not only represents a valid alternative to the traditional landfilling, but it also reduces cement consumption. Considering that the above-mentioned applications require high volumes of raw material, this solution represents a mechanical, environmental and cost-effective alternative to conventional binders (e.g. Portland cement). However, additional environmental studies are required to validate this technique in terms of leaching of contaminants into the soil, a nuance which is especially relevant considering the high values of $\mathrm{SO}_{3}$ present in the original constitution of the tailings.

The authors would like to acknowledge the contribution of the company PEGOP, for the supply of fly ash.

\section{References}

1. F. Pacheco-Torgal, J. Castro-Gomes, S. Jalali, Cement Concrete Res. 37, 6 (2007)

2. F. Pacheco-Torgal, J. Castro-Gomes, S. Jalali, Constr. Build. Mater. 22, 6 (2008)
3. F. Pacheco-Torgal, J. Castro-Gomes, S. Jalali, Constr. Build. Mater. 23, 1 (2009)

4. F. Pacheco-Torgal, J. Castro-Gomes, S. Jalali, J. Mater. Civil Eng. 22, 9 (2010)

5. G. Kastiukas, X. Zhou, J. Castro-Gomes, J. Mater. Civil Eng. 29, 10 (2017)

6. F. Kuranchie, S. Shukla, D. Habibi, Int. J. Min. Reclam. Env. 30, 2 (2016)

7. S. Ahmari, L. Zhang, Constr. Build. Mater. 40, 3 (2013)

8. S. Ahmari, L. Zhang, Constr. Build. Mater. 29, 4 (2012)

9. S. Ahmari, L. Zhang, Constr. Build. Mater. 44, 7 (2013)

10. L. Zhang, S. Ahmari, J. Zhang, Constr. Build. Mater. 25, 9 (2011)

11. J. Kiventera, L. Golek, J. Yliniemi, V. Ferreira, J. Deja, M. Illikainen, Int. J. Miner. Process. 149, 9 (2016)

12. N. Cristelo, S. Glendinning, T. Miranda, D. Oliveira, R. Silva, Constr. Build. Mater. 36, 11 (2012)

13. BSi EN 12457-7, Characterisation of waste Leaching - Compliance test for leaching of granular waste materials and sludges, $\mathrm{Br}$. Stand. Institution, London (2004) 